\title{
Plant-Based Milks: Rice ${ }^{1}$
}

\section{Meagan Lamothe, Daniela Rivero-Mendoza, and Wendy J. Dahl²}

Rice milk is a plant-based, non-dairy beverage made primarily from milled rice and water. It is marketed as an allergy-friendly, easy-to-digest, vegan substitute for cow's milk (DREAM n.d.-a). Similar to other plant-based beverages, rice milk usually has an opaque white or beige color and creamy texture resembling that of cow's milk (Makinen et al. 2016). This publication describes how rice milk is made, its ingredients and nutrient profile, and potential health benefits and risks of consumption.

\section{How is rice milk made?}

The industrial process of making rice milk involves a number of steps. First, the rice grains are milled, either fully or partially. "Fully milled" indicates that the husk, germ, and bran have been removed, and only white rice remains, whereas "partially milled" signifies that only the husk has been removed, and thus brown rice remains. The fully milled process may create the optimal texture, but it also results in losses of vitamins, minerals, and fiber (Muthayya et al. 2014). Next, the milled rice is ground, made into a slurry by combining with water, and filtered to remove any particles that are too large or coarse (Makinen et al. 2016). The remaining slurry is treated with enzymes to partially break down the starch and facilitate a suspension mixture. When the desired viscosity (thickness) is reached, other ingredients are added, such as oil, salt, stabilizers, vitamins, minerals, flavors, and sweeteners. After the addition of oil, an emulsion is produced through homogenization, which creates creaminess and stability of the rice milk (Makinen et al. 2016). Although commercially produced rice milk can typically be found at major grocery chains and health food stores, there are also many simple online recipes for making rice milk with basic ingredients in a home kitchen.

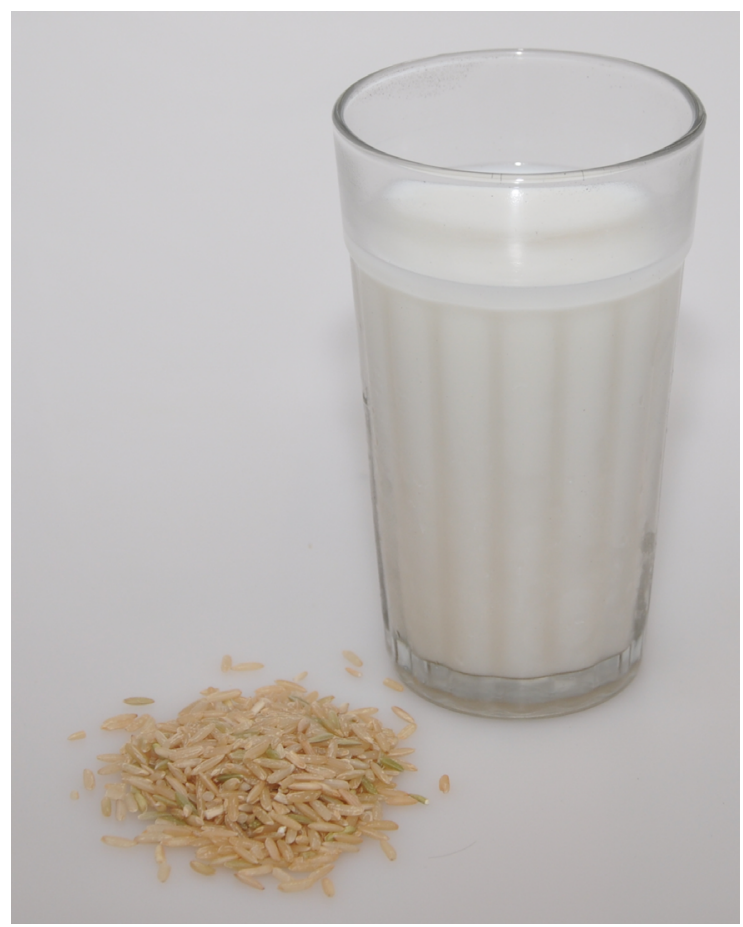

Credits: Lincoln Zotarelli, UF/IFAS

In most commercial brands of rice milk, the first four ingredients are water, milled rice, vegetable oil (canola, sunflower, or safflower), and salt (DREAM n.d.-d). In some rice milk varieties, there may be additional ingredients. These can include natural or artificial flavors, such as vanilla and chocolate; thickeners, such as xanthan gum,

1. This document is FSHN20-50, one of a series of the Food Science and Human Nutrition Department, UF/IFAS Extension. Original publication date October 2020. Visit the EDIS website at https://edis.ifas.ufl.edu for the currently supported version of this publication.

2. Meagan Lamothe, graduate student, Food Science and Human Nutrition Department; Daniela Rivero-Mendoza, Extension and research coordinator; and Wendy J. Dahl, associate professor, Food Science and Human Nutrition Department; UF/IFAS Extension, Gainesville, FL 32611. 
tapioca starch, or carrageenan; and vitamins and minerals for nutrient fortification, such as calcium phosphate and vitamins $\mathrm{A}, \mathrm{D}$, and B12 (DREAM n.d.-b).

\section{How does the nutrient profile of rice milk compare to cow's milk?}

Table 1 summarizes the nutrient profiles for a $1 \mathrm{cup}(8 \mathrm{oz})$ serving of rice milk and whole and low-fat cow's milk. This comparison assumes that the rice milk is unflavored but fortified with calcium and vitamins $\mathrm{A}, \mathrm{D}$, and B12.

Calories. A serving of cow's whole milk contains about 150 calories (USDA n.d.), whereas a serving of rice milk is about 120 calories (DREAM n.d.-c). However, fat-free and low-fat cow's milk contain fewer calories than rice milk (USDA n.d.).

Protein. A serving of cow's milk (either whole, skim, or low-fat) contains about $8 \mathrm{~g}$ of protein (USDA n.d.), whereas a serving of rice milk contains less than $1 \mathrm{~g}$ of protein (DREAM n.d.-c).

Fat. A serving of whole cow's milk contains about $8 \mathrm{~g}$ of fat, of which more than half is saturated fat (USDA n.d.). A serving of rice milk contains a similar amount of fat as low-fat milk but no saturated fat (DREAM n.d.-c).

Carbohydrates. An $8 \mathrm{oz}$ serving of whole or low-fat cow's milk contains about 12 to $13 \mathrm{~g}$ of total carbohydrate, almost all of which is in the form of the naturally occurring milk sugar, lactose (Singhal, Baker, and Baker 2017). An 8 oz serving of rice milk contains about $23 \mathrm{~g}$ of total carbohydrates, of which about $10 \mathrm{~g}$ is added sugar (DREAM n.d.-c). The remaining $13 \mathrm{~g}$ of carbohydrate is starch. Most commercial rice milks contain no fiber.

Vitamins and Minerals. Commercially produced, fortified rice milks may contain similar levels of calcium, vitamins A, D, and B12 as cow's milk (USDA n.d.), because these nutrients have been added to the beverage during the production process. Unfortified rice milk (without any added vitamins and minerals), such as homemade rice milk, is not a source of these nutrients (DREAM n.d.-d).

\section{What are the potential health benefits of rice milk?}

Rice milk is safe for people who have allergies to cow's milk, because it does not contain any milk protein. In the United States, foods that contain any of the eight major food allergens-or proteins derived from these foods-must include a disclosure on the label (FDA 2018). Dairy is the most common major food allergen. Allergies to soy and tree nuts, the base ingredients of other plant-based milks, are also common (FDA 2018). Although allergy to rice is possible, rice is not among the common allergens in the United States, making rice milk a safe choice for many people with allergies to dairy, soy, or nuts.

Because rice milk does not contain any lactose, it is suitable for adults with lactose intolerance. Lactose-free cow's milk is also suitable for individuals with lactose intolerance and is widely available in the United States.

Rice milk also contains no saturated fat or cholesterol (Singhal, Baker, and Baker 2017). The Dietary Guidelines for Americans recommend limiting intake of saturated fat to less than $10 \%$ of total calorie intake per day, so rice milk fits well within this guideline (USDA 2015). Note that low-fat and fat-free cow's milk also align with the DGA recommendation, because these products are low in saturated fat.

\section{What are the possible risks of rice milk?}

Rice milk contains nearly twice as many grams of carbohydrates per serving as cow's milk, including about $10 \mathrm{~g}$ of sugars per serving. It is recommended in the Dietary Guidelines for Americans to limit intake of sugar-containing beverages. In contrast, low-fat or skim cow's milk are free of added sugars and thus are healthful choices. The glycemic index of rice milk is also about twice that of cow's milk, meaning it leads to a higher increase in blood glucose after consumption (University of Sydney n.d.). Rice milk may not be the best choice for individuals with diabetes or at risk for diabetes, who are trying to limit intake of carbohydrates and manage their blood glucose.

A possible health risk of consuming rice milk is its potentially high levels of arsenic (Wilson 2015). Arsenic is a toxic metal that occurs naturally in the soil and water and can subsequently enter the food supply through plants. Rice tends to absorb higher amounts of arsenic than other grains and can sometimes reach dangerous levels if it is not monitored closely. In the United States, the Food and Drug Administration (FDA) conducts testing of foods to ensure limited consumer exposure to arsenic from rice and other foods (FDA 2019). For this reason, it is likely that commercially available rice milks available in the United States are not high in arsenic, but it may be prudent to consume rice and rice-containing products, including rice milk, in moderation. 


\section{Is rice milk an appropriate choice for children?}

Rice milk has been suggested as a substitute for cow's milk for children with milk protein allergies (Tzifi, Grammeniatis, and Papadopoulous 2014). If a child is consuming a vegan diet, fortified rice milk does provide a source of some of the essential nutrients commonly found in dairy: calcium, vitamin A, vitamin D, and vitamin B12 (DREAM n.d.-c). However, rice milk provides very little protein-another much-needed nutrient for child growth. The addition of an appropriate protein powder, such as soy or pea, to rice milk may be needed to ensure adequate protein intake and proper growth and development (Baroni, Goggi, and Battino 2018). Additionally, it is important to note that caution should be taken regarding the amount of rice milk a child drinks due to the risk of arsenic toxicity, as discussed above (Carignan et al. 2016).

Rice milk should not be fed to infants. Infants should be fed human milk, or in the absence of human milk, an appropriate infant formula.

\section{Summary}

Rice milk is a plant-based, non-dairy beverage. Compared to cow's milk, rice milk is much lower in protein and higher in carbohydrate. If fortified, rice milk provides similar amounts of calcium and vitamins A, D, and B12 as cow's milk. The sugar and starch content of rice milk contributes to its high glycemic index. Because it provides little protein and is a potential source of arsenic, caution should be exercised when considering rice milk as a beverage for children.

\section{References}

Baroni, L., S. Goggi, and M. Battino. 2018. "Planning Well-Balanced Vegetarian Diets in Infants, Children, and Adolescents: The Vegplate Junior." Journal of Academy of Nutrition and Dietetics 119 (7): 1067-1073.

Carignan, C. C., T. Punshon, M. R. Karagas, and K. L. Cottingham. 2016. "Potential Exposure to Arsenic from Infant Rice Cereal." Annals of Global Health 82 (1): 221-224.

DREAM. n.d.-a. “Base Ingredient: Rice.” Accessed 2 April 2020. http://www.dreamplantbased.com/education

DREAM. n.d.-b. "Dream Products: Base Ingredient Rice." Accessed 20 April 2019. http://www.dreamplantbased.com/ base/rice/
DREAM. n.d.-c. "Rice Dream: Enriched Original Rice Drink.” Accessed 2 April 2020. http://www.dreamplantbased.com/product/ rice-dream-enriched-original-organic-rice-drink/

DREAM. n.d.-d. "Rice Dream: Original Rice Drink." Accessed 2 April 2020. http://www.dreamplantbased.com/ product/rice-dream-classic-original-organic-rice-drink/

Food and Drug Administration (FDA). 2018. "Food Allergies: What You Need to Know.” Accessed 2 April 2020. https://www.fda.gov/Food/ResourcesForYou/Consumers/ ucm079311.htm

Food and Drug Administration (FDA). 2019. "Arsenic in Food and Dietary Supplements." Accessed 2 April 2020. https://www.fda.gov/food/metals-and-your-food/ arsenic-food-and-dietary-supplements

Makinen, O. E., V. Wanhalinna, E. Zannini, and E. K. Arendt. 2016. "Foods for Special Dietary Needs: Non-dairy Plant-Based Milk Substitutes and Fermented Dairy-Type Products." Critical Reviews in Food Science and Nutrition 56 (3): 339-349.

Muthayya, S., J. D. Sugimoto, S. Montgomery, and G. F. Maberly. 2014. "An Overview of Global Rice Production, Supply, Trade, and Consumption." Annals of the New York Academy of Sciences 1324:7-14.

Singhal, S., R. D. Baker, and S. S. Baker. 2017. "A Comparison of the Nutritional Value of Cow's Milk and Nondairy Beverages." Journal of Pediatric Gastroenterology and Nutrition 64 (5): 799-805.

Tzifi, F., V. Grammeniatis, and M. Papadopoulos. 2014. "Soy- and Rice-Based Formula and Infant Allergic to Cow's Milk." Endocrine, Metabolic \& Immune Disorders - Drug Targets 14 (1): 38-46.

United States Department of Agriculture (USDA). 2015. "Dietary Guidelines for Americans 2015-2020." Accessed 2 April 2020. https://health.gov/our-work/ food-nutrition/2015-2020-dietary-guidelines/guidelines/.

United States Department of Agriculture (USDA). n.d. FoodData Central. Accessed 2 April 2020. https://ndb.nal. usda.gov/ndb/foods

University of Sydney. n.d. GI Foods Advanced Search. Accessed 2 April 2020. Available from http://glycemicindex. com/foodSearch.php 
Wilson, D. 2015. "Arsenic Consumption in the United

States." The Journal of Environmental Health 78 (3): 8-14.

Table 1. Nutrient profiles of fortified, unflavored rice milk compared to cow's milk.

\begin{tabular}{|c|c|c|c|c|}
\hline & $\begin{array}{l}\text { Fortified rice milk } \\
\qquad(1 \text { cup) }\end{array}$ & $\begin{array}{l}\text { Fat-free skim milk } \\
\qquad(1 \text { cup) }\end{array}$ & $\begin{array}{l}\text { Low-fat ( } 1 \%) \text { milk } \\
\text { (1 cup) }\end{array}$ & $\begin{array}{c}\text { Whole milk } \\
\text { (1 cup) }\end{array}$ \\
\hline Energy (Calories) & 120 & 83 & 102 & 150 \\
\hline Protein (g) & 1 & 8 & 8 & 8 \\
\hline Total fat (g) & 2.5 & 0 & 2.4 & 8 \\
\hline Saturated fat (g) & 0 & 0.1 & 1.5 & 4.5 \\
\hline Carbohydrate (g) & 23 & 12 & 12 & 12 \\
\hline Fiber (g) & 0 & 0 & 0 & 0 \\
\hline Total sugars (g) & 10 & 12 & 12 & 12 \\
\hline Vitamin A (mcg) & 80 & 149 & 142 & 112 \\
\hline Vitamin B12 (mcg) & 0.6 & 1 & 1 & 1 \\
\hline Vitamin D (mcg) & 3.8 & 3 & 3 & 3 \\
\hline Calcium (mg) & 300 & 298 & 305 & 276 \\
\hline Sodium (mg) & 100 & 102 & 107 & 105 \\
\hline Potassium (mg) & NR & 381 & 366 & 322 \\
\hline
\end{tabular}

